\title{
PEMBELAJARAN MENGANALISIS TEKS DESKRIPSI MODEL NUMBERED HEAD TOGETHER PADA SISWA KELAS VII SMP SIVALIPUTTA
}

\author{
Wawan Iswanto, Ahmad Rabi’ul Muzammil, Agus Syahrani \\ Program Studi Pendidikan Bahasa dan Sastra Indonesia \\ FKIP Untan Pontianak \\ Email:wawaniswanto1933@gmail.com
}

\begin{abstract}
This study provides an overview of the application of the numbered head together model in learning to analyze content and the supporting factors of the NHT model in descriptive text learning. The results of this study indicate that the application of the NHT model in learning to analyze the content of descriptive text is carried out in four meetings and includes six activities. In 1-3 meetings, preparatory activities, group formation, problem discussions, questions and answers, giving conclusions, and awards were carried out during the learning process to analyze the content of the descriptive text including: type, structure and language in the waterfall description text. The 4th meeting was held to assess the results of the individual analysis of the descriptive text entitled The Beauty of the Blue Lake among the Hills. The factors that support the success of learning are: competent teachers and careful planning stages in lesson plans, students who are enthusiastic about learning to analyze the content of descriptive texts, learning objectives that make students like descriptive texts, learning materials that are close to students, NHT methods, various media learning, learning evaluation of processes and products.
\end{abstract}

Keywords: Analyze, Descriptive Text, Numbered Head Together.

\section{PENDAHULUAN}

Keterampilan menganalisis dalam kompetensi dasar Bahasa Indonesia, merupakan kemampuan atau kreativitas yang memuat sejumlah kegiatan seperti mengurai, membedakan, memilah sesuatu untuk digolongkan dan dikelompokkan kembali menurut kriteria tertentu kemudian dicari kaitannya dan ditafsirkan maknanya pada materi tertentu, misalnya pada materi teks deskripsi. Adapun di dalam rancangan penelitian ini, peneliti ingin melakukan kajian mengenai kemampuan siswa dalam memahami isi teks deskripsi berdasarkan kompetensi menganalisis.

Berdasarkan pra observasi yang telah dilakukan di SMP Sivaliputta Kabupaten Kubu Rayapada tanggal 22 Agustus 2019 diperoleh informasi bahwa pembelajaran pada aspek menganalisis isi teks deskripsi yang diadakan di sekolah kurang optimal serta belum memenuhi Kriteria Ketuntasan Minimal (KKM). Hal ini terbukti dari Kriteria Ketuntasan Minimal (KKM) yang distandarkan oleh SMP Sivaliputta sebesar 70, hasil nilai tugas yang diperoleh masih terdapat siswa yang berada di bawah (KKM). Rata-rata penguasaan siswa kelas VII di SMP Sivaliputta sebanyak 10 siswa (48\%) yang mencapai KKM dan sebanyak 11 siswa (52\%) masih di bawah KKM. Rendahnya nilai menganalisis isi teks deskripsi di atas disebabkan oleh beberapa faktor yaitu: (1) guru mengajar masih menggunakan metode ceramah; (2) guru mengajar masih bersifat teoritis, (3) guru mengajar masih berpusat pada guru. Guru dituntut untuk kreatif atau 
inovatif dalam menyajikan bahan pelajaran yang akan disampaikan kepada siswa dengan menggunakan model pembelajaran yang tepat, satu di antara model pembelajaran yang dapat memotivasi atau membuat siswa menjadi lebih aktif dan tekun dalam belajar adalah model pembelajaran kooperatif tipe Numbered Head Together (NHT), karena pembelajaran kooperatif dapat melatih dan membiasakan siswa untuk saling berbagi pengetahuan, pengalaman, tugas dan tanggung jawab.

Berdasarkan paparan di atas, alasan memilih model pembelajaran Numbered Head Together (NHT) dalam menganalisis isi teks deskripsi yaitu: (1) model pembelajaran NHT mampu mendorong siswa untuk membagikan idenya dan dapat meningkatkan kerja sama mereka. (2) model pembelajaran ini belum diterapkan di SMP Sivaliputta. Model pembelajaran yang diterapkan atau digunakan oleh guru memiliki pengaruh terhadap kemampuan peserta didik atau siswa di dalam kelas. Hal inilah yang mendorong serta memotivasi peneliti untuk mengetahui tingkat keberhasilan dalam penerapan model pembelajaran Numbered Head Together (NHT) terhadap kemampuan menganalisis isi teks deskripsi pada siswa kelas VII di SMP Sivaliputta Kabupaten Kubu Raya.

Berdasarkan latar belakang di atas, maka rumusan masalah dalam penelitian ini dapat dirumuskan sebagai berikut: (1) bagaimanakah penerapan model Numbered Head Together (NHT) dalam pembelajaran menganalisisi isi teks deskripsi kelas VII SMP Sivaliputta?; dan (2) Faktor-faktor yang mendukung keberhasilan model Numbered Head Together (NHT) dalam pembelajaran menganalisis isi teks deskripsi kelas VII SMP Sivaliputta?. Tujuan penelitian ini secara khusus dirumuskan sebagai berikut: (1) mendeskripsikan penerapan model Numbered Head Together (NHT) dalam pembelajaran menganalisisi isi teks deskripsi kelas VII SMP Sivaliputta; dan (2) mendeskripsikan faktor-faktor yang mendukung keberhasilan model Numbered Head Together (NHT) dalam pembelajaran isi teks deskripsi kelas VII SMP Sivaliputta.

Model pembelajaran Numbered Head Together (NHT) merupakan salah satu pembelajaran kooperatif dengan sintaksis: pengarahan, buat kelompok heterogen dan tiap siswa memiliki nomor tertentu, berikan persoalan materi bahan ajar (untuk tiap kelompok sama tetapi tiap siswa tidak sama sesuai dengan nomor siswa, tapi siswa dengan nomor sama mendapat tugas yang sama), kemudian bekerja kelompok, prestasi kelompok dengan nomor siswa yang sama sesuai tugas masing-masing sehingga terjadi diskusi kelas, kuis individu, dan buat skor perkembangan tiap siswa, umumkan hasil kuis dan beri reward.

Trianto menyatakan bahwa model Numbered Head Together (NHT) atau penomoran berfikir bersama merupakan jenis pembelajaran kooperatif yang dirancang untuk mempengaruhi pola interaksi siswa dan sebagai alternatif terhadap struktur kelas tradisional (Trianto, 2016, p.62). Wijayati, dan Mahmud (2008, p.282) mengungkapkan bahwa:

"model pembelajaran NHT merupakan bagian dari model pembelajaran kooperatif yang identik dengan kerja kelompok."

Sedangkan Indris mengungkapkan bahwa model pembelajaran NHT merupakan model pembelajaran yang memberikan kesempatan kepada siswa untuk membagikan ide-ide dan mempertimbangkan jawaban yang paling tepat (Indris, 2014, p.31). Berdasarkan pendapat para ahli di atas dapat disimpulkan bahwa model NHT adalah bagian model pembelajaran kooperatif, yang menekankan pada stuktur-struktur khusus yang dirancang untuk mempengaruhi pola interaksi siswa yang lebih mengedapankan kepada aktivitas siswa dalam mencari, mengolah, dan melaporkan informasi dari berbagai sumber.

Langkah-langkah pelaksana model pembelajaran NHT harus dilakukan melalui 
langkah yang sistematis agar dapat mencapai tujuan pembelajaran yang maksimal. Shoimin mengungkapkan bahwa langkah-langkah pelaksana model NHT sebagai berikut: (1) siswa dibagi dalam kelompok; (2) guru memberikan tugas dan tugas masing-masing kelompok mengerjakan; kelompok mendiskusikan; (4) guru memanggil perawakilan kelompok untuk diskusi; (5) guru meminta kelompok lain menanggapi; dan (6) kelompok menyimpulkan hasil diskusi.

Menurut Sugiono menganalisis adalah aktivitas yang memuat sejumlah kegiatan seperti mengurai, membedakan, memoliah sesuatu untuk digolongkan dan dikelompokan kembali menurut kriteria tertentu kemudian dicari kaitannya dan ditafsir maknanya (Sugiono, 2015, p.335). Teks deskripsi merupakan sejumlah unit simbol kebahasaan yang digunakan untuk mewujudkan realitis pengalaman dan logika (ideasional), realitas sosial (interpersonal), dan sekaligus realitas tekstual/semiotik (simbol).

Berdasarkan teori analisis dan teks deskripsi di atas akan dilakukan penelitian mengenai dokumentasi dalam proses pembelajaran menganalisis isi teks deskripsi pada siswa kelaas VII di SMP Sivaliputta yang merupakan bagian dari materi mata pelajaran Bahasa Indonesia semester satu dengan Kompetensi Dasar (KD) 4.1 Menganalisis dan menjelaskan isi teks deskripsi objek (tempat wisata, tempat, bersejarah, pentas seni daerah, kain tradisional, dll) yang dibaca secara lisan merujuk pada jenis-jenis, struktur, dan kebahasaan.

Teks deskripsi merupakan jenis teks yang bertujuan untuk menggambarkan suatu objek (benda, makhluk hidup, tempat, atau peristiwa) secara nyata sesuai dengan apa yang dilihat, didengar, dirasa, dicium, dan diraba dari objek tersebut.

\section{METODE PENELITIAN}

Penelitian ini menggunakan metode deskriptif, metode ini dipergunakan karena penelitian ini dilakukan untuk menggambarkan atau mendeskripsikan penerapan dan faktor-faktor yang mendukung keberhasilan model NHT dalam pembelajaran menganalisis isi teks deskripsi kelas VII SMP Sivaliputta. Hal ini selaran dengan pendapat Zuldafrial (2009, p.22) mengungkapkan bahwa"

"metode deskriptif adalah suatu metode yang dipergunakan di dalam memecahkan masalah penelitian dengan cara menggambarkan atau melukiskan keadaan subjek penelitian pada saat sekarang berdasarkan fakta-fakta tampak atau sebagaimana adanya."

Bentuk penelitian yang digunakan dalam penelitian ini adalah studi survei (survey studies). Penelitian survei digunakan karena teori yang mendukung hipotesis belum ada dan penulis tidak memberikan perlakuan (Sugiyono, 2008, p.11). Maka penelitian ini dapat dikategori sebagai penelitian eks post facto. Penelitiaan ex post facto dilakukan untuk meneliti peristiwa yang telah terjadi dan kemudian meruntut ke belakang melalui data untuk menentukan fakta-fakta yang mendahului atau diperkirakan menjadi penyebab peristiwa yang diteliti. Partisipan adalah orang-orang yang diajak wawancara, observasi, diminta memberikan data, pendapat, pemikiran, persepsi. Teknik kualitatif dipakai sebagai pendekatan dalam penelitian iniAdapun yang dimaksud dengan data kualitatif dalam skripsi ini seperti; gambaran umum sekolah, letak geografis, tujuan, sasaran- prasarana, perangkat dan media pembelajaran, pelaksanaan pembelajaran menaganlisis isi teks deskriptif pada siswa kelas VII Sivaliputta Kabupaten Kubu Raya. Subjek penelitian ini adalah guru mata pelajaran Bahasa Indonesia kelas VII SMP Sivaliputta. Objek penelitian ini adalah pembelajarna menganalisis isi teks deskriptif dengan model Numbered Head Together (NHT).

Teknik pengumpulan data adalah cara peneliti dalam mendapatkan sejumlah 
data lapangan yang kemudian dideskripsikan. Sesuai dengan bentuk pendekatan penelitian kualitatif dan sumber data yang akan digunakan, maka teknik pengumpulan data yang digunakan dengan observasi atau pengamatan partisipatif (langsung), analisis dokumen, dan wawancara. Prosedur penelitian merupakan tahapan atau langkah-langkah yang harus ditempuh dalam melaksanakan suatu penelitian. Kegiatan penelitian ini dilaksanakan meliputi beberapa tahapan, yaitu sebagai berikut: tahap persiapan, tahap pelaksana, dan tahap akhir.

Teknik analisis data yang digunakan dalam penelitian ini adalah: (1)

berdasarkan sub masalah pertama, bagian ini akan dibahas proses pembelajaran menganalisis isi teks deskripsi di kelas VII SMP Sivaliputta menggunakan model NHT.; dan (2) berdasarkan sub masalah kedua, bagian ini akan dibahas proses mengungkapkan faktor-faktor yang menyebabkan kebehasilan model NHT mencangkup: guru, siswa, tujuan, materi, metode, media, dan evaluasi. Adapun cara pengumpulan data melalui pengamatan, wawacara, dan dokumentasi.

\section{HASIL PENELITIAN DAN PEMBAHASAN}

\section{Hasil}

Setting penelitian pada tempat dilaksanakan di SMP Sivaliputta pada ruang kelas VII dengan jumlah 21 orang berdasarkan rincian laki-laki ( 7 siswa) dan perempuan (14 siswa). Beralamat di Jalan Parit Nomor II, Gang Flamboyan III B, Nomor 9, Kecamatan Sungan Raya, Kabupaten Kubu Raya. Waktu penelitian dimulai pada 22 Agustus-6 September 2019. Penerapan model NHT dalam pembelajaran menganalisis isi teks deskripsi kelas VII SMP Sivaliputta memiliki dua aspek penerapan yaitu (1) pembelajaran menganalisis isi teks deskripsi yaitu menggunakan kompetensi dasar (4.1) menganalisis isi teks deskripsi yaitu menentukan dan menjelaskan jenisjenis, struktur, dan kebahasaan teks deskripsi pada objek tempat wisata yang dibaca.; (2) berfikir sistematis dan kritis sebagai hasil penerapan model NHT dalam pembelajaran menganalisis isi teks deskripsi dengan cara belajar berkelompok guna memperoleh kebehasilan berfikir sistematis dan kritis siswa untuk saling berbagi gagasan dan mempertimbangkan jawaban yang tepat pada penugasan kelompok maupun secara individu dalam ketepatan analisis isi teks deskripsi yang dijelaskan pada (Tabel 1) berikut:

Tabel 1. Langkah-Langkah Pelaksanaan Model NHT

\begin{tabular}{|c|c|c|}
\hline No. & Langkah-Langkah & Deskripsi \\
\hline 1. & Persiapan (preparation) & $\begin{array}{l}\text { Guru mempersiapkan rancangan } \\
\text { pelajaran meliputi: RPP, materi } \\
\text { menganalisis isi teks deskripsi, LKS, } \\
\text { kuis. }\end{array}$ \\
\hline 2. & $\begin{array}{l}\text { Pembentukan kelompok } \\
\text { (group formation) }\end{array}$ & $\begin{array}{l}\text { Guru membagi siswa menjadi beberapa } \\
\text { kelompok yang beranggotakan } 4-5 \\
\text { orang siswa. }\end{array}$ \\
\hline & Diskusi masalah (discussion) & $\begin{array}{l}\text { Guru membagikan lembar kerja siswa } \\
\text { kepada setiap kelompok sebagai bahan } \\
\text { yang akan dipelajari. }\end{array}$ \\
\hline & $\begin{array}{l}\text { Pemberian jawaban (answer } \\
\text { the question) }\end{array}$ & $\begin{array}{l}\text { Guru menyebut nomor dan siswa dari } \\
\text { tiap kelompok menyiapkan jawaban } \\
\text { kepada siswa di kelas. }\end{array}$ \\
\hline & $\begin{array}{l}\text { Memberi kesimpulan } \\
\text { (conclusion) }\end{array}$ & $\begin{array}{l}\text { Guru memberikan simpulan atau } \\
\text { jawaban akhir dari semua pertanyaan } \\
\text { yanng diberikan. }\end{array}$ \\
\hline
\end{tabular}




\begin{tabular}{lll}
\hline 6. & Memberikan penghargaan \\
(appreaciation) & $\begin{array}{l}\text { Guru memberikan penghargaan berupa } \\
\text { kalimat pujian disertai hadiah berupa } \\
\text { alat tulis dan penilaian atas kemampuan } \\
\text { yang dimiliki. }\end{array}$ \\
\hline
\end{tabular}

Faktor pendukung keberhasilan Sivaliputta menggunakan model NHT pembelajaran menganalisis isi teks dapat dijelaskan berdasarkan (Tabel 2) di deskripsi pada siswa kelas VII di SMP bawah:

Tabel 2. Faktor Pendukung Pembelajaran Menggunakan Model NHT

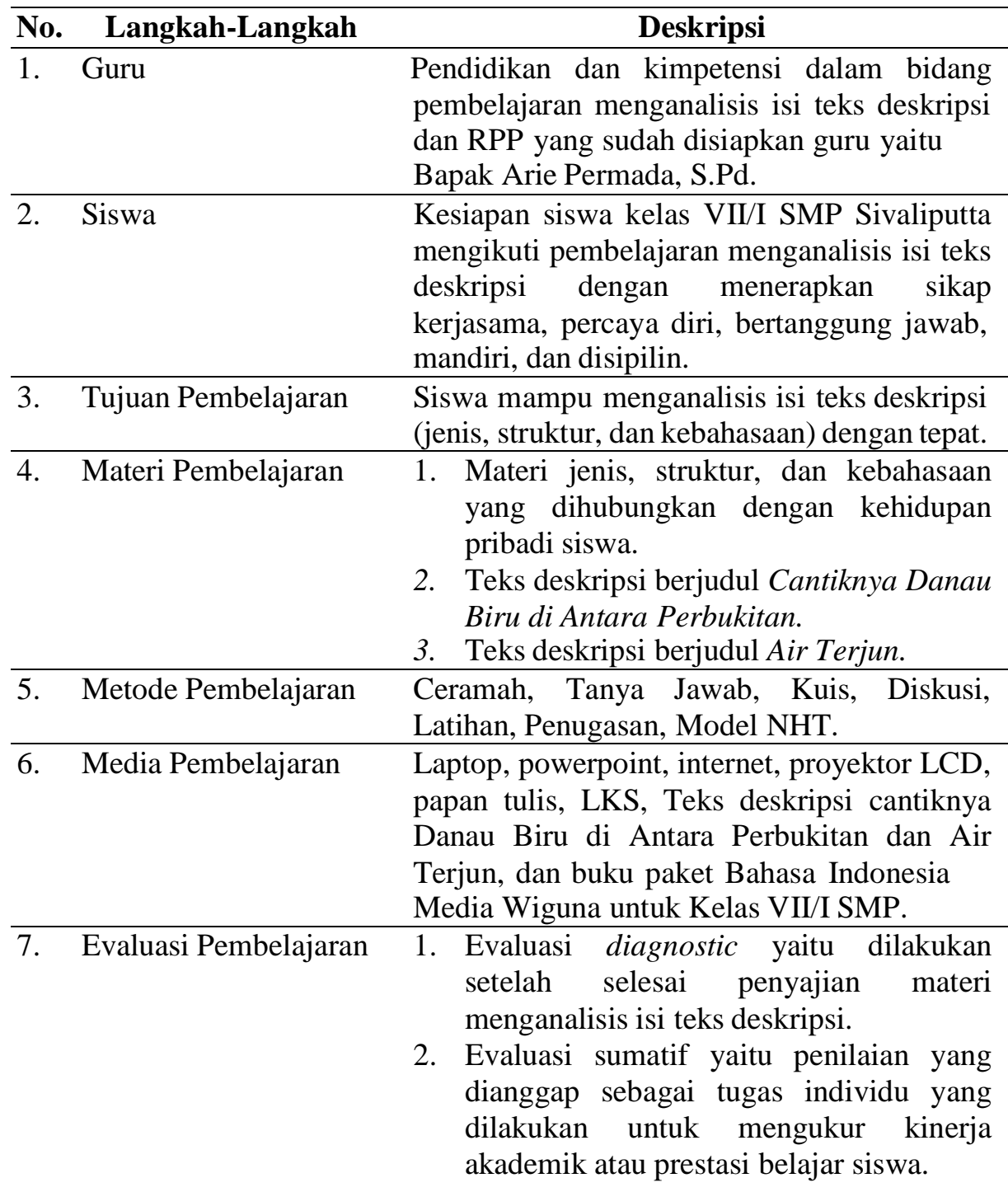

\section{Pembahasan}

Penerapan model NHT dalam pembelajaran menganalisis isi teks deskripsi kelas VII SMP Sivaliputta berdasarkan proses pembelajaran dilakukan dengan tiga langkah yaitu (1) menentukan dan menjelaskan jenis-jenis teks dekskripsi, proses pembelajaran dilakukan pada Selasa, 27 Agustus 2019, pukul 9.30-10:50 menggunakan pembelajaran model NHT. Selanjutnya guru memberikan tugas individu pada Kamis, 5 September 2019, 
pukul 8:00-9:20 untuk menentukan dan menjelaskan jenis-jenis teks deskripsi Cantiknya Danau Biru di Antara Perbukitan kepada siswa.; (2) menentukan dan menjelaskan struktur teks deskripsi, proses pembelajaran dilakukan pada Kamis, 29 Agustus 2019, Pukul 8:00-9:20 menggunakan pembelajaran model NHT. Selanjutnya guru memberikan tugas individu pada Kamis, 5 September 2019, pukul 8:00-9:20 untuk menentukan struktur teks deskripsi.; dan (3) menentukan dan menjelaskan kebahasaan teks deskripsi, proses pembelajaran dilakukan pada Selasa, 3 September 2019, pukul 9:30-10:50. Selanjutnya penugasan individu pada Kamis, 5 September 2019, pukul 8:00-9:20 untuk menentukan dan menjelaskan kebahasaan teks deskripsi Cantiknya Danau Biru di Antara Perbukitan kepada siswa.

Penerapan model NHT pada pembelajaran menganalisis isi teks deskripsi dilakukan dengan berfikir sistematis dan kritis. Penerapan ini membuat siswa lebih kreatif karena menuntut siswa mampu menyelesaikan masalah secara bersama maupun individu, bekerja dengan target dan keterabatasan waktu. Ada enam langkah yang harus ditempuh untuk menghasilkan proses pembelajaran menganalisis isi teks deskripsi menggunakan model NHT yaitu (1) persiapan yang sudah lengkap berdasarkan RPP dan media yang digunakan, (2) pembentukan kelompok yang meliputi (gunung bawang, gunung kelam, bukit jamur, dan gunung pancong).;

(3) diskusi masalah dengan penilaian berdasarkan indikator (kerjasama kelompok, uraian yang dituliskan jelas dan tepat, distribusi pendapat dalam kelompok, menjawab pertanyaan, sikap dalam berpendapat, kreativitas, bertanya, kerapian, kelengkapan jawaban, ketepatan analisis isi teks deskripsi, kedalaman analisis) adapun diperoleh kelompok gunung bawang mengalami beberapa kekeliruan terhadap pelaksanaan diskusi.; (4) pemberian jawaban, guru memberikan sembilan pertanyaan kepada siswa menggunakan model NHT, dengan perolehan 7 siswa (33\%) dengan tingkat kemampuan cukup dan 14 siswa (67\%) dengan tingkat kemampuan baik.; (5) memberikan simpulan, guru meminta beberapa siswa dari perwakilan setiap kelompok untuk memberikan kesimpulan proses pembelajaran yang sudah berlangsung, diperoleh semua perwakilan kelompok sudah tepat dengan jawaban yang jelas dan benar dalam menjawab pertanyaan yang diberikan.; (6) memberikan penghargaan, guru memberikan penghargaan berupa pernyataan lisan yang mengadung kalimat positif dan nilai pada siswa secara individu, sedangkan siswa yang mendapatkan predikat cukup diberikan pembelajaran atau tugas tambahan. Selanjutnya guru memberikan penghargaan berupa pernyataan lisan yang mengadung kalimat positif disertai hadiah berupa alat tulis kepada kelompok bukit jamur dan gunung pancong. Penghargaan ini diberikan agar siswa secara individu dan kelompok lebih termotivasi dalam belajar menganalisis isi teks deskripsi.

Faktor pendukung keberhasilan pembelajaran menganalisis isi teks deskripsi dengan Model NHT terhadap siswa kelas VII SMP Sivaliputta meliputi guru, siswa, tujuan pembelajaran, materi pembelajaran, metode pembelajaran, media pembelajara, dan evaluasi pembelajaran.

Guru Bapak Arie Permada S,Pd. selaku guru mata pelajaran Bahasa Indonesia yang mengajar di kelas VII sangat aktif dalam memotivasi siswa untuk berekspresi dan berkreativitas dalam berbagai kegiatan bahasa khususnya menulis. Bapak Arie mendukung siswa dengan cara berpatisipasi selama siswa berani berfikir kritis dan mampu menanggapi masalah secara intensif membimbing siswa dalam kegiatan menganalisis isi teks deskripsi.

Bapak Arie memiliki kharakteristik dalam setiap proses pembelajarannya di kelas yaitu mengutamakan mengajari siswa berpikir kritis dan siap menghadapi masalah 
untuk dipecahkan. Seperti yang terungkap dalam wawancara, berikut kutipannya:

"Selama saya mengajar bukan sekedar memberikan ilmu yang ada dibuku, tetapi saya juga mencoba membuat siswa mengikuti jejak saya untuk berani seperti saya yaitu berpikir kritis dan mampu memecahkan masalah dengan cara apapun, termasuk pengalaman belajar menganalisis isi teks deskripsi yang saya ajarkan menggunakan model NHT. Semua ini dilakukan bertujuan sebagai pengalaman yang saya berikan guna kesiapan siswa untuk pembelajaran selajutnya kapanpun dan dimanapun."

Berdasarkan kutipan tersebut, tentuk hal ini merupakan bentuk kecintaan guru terhadap teks deskrips agar siswa juga memiliki rasa yang sama terhadap materi teks deskripsi, sehingga meghilangkan rasa egois ketika belajar.

Siswa kelas VII merupakan siswa yang aktif mengikuti pembelajaran menganalisis isi teks deskripsi. Selama pelajaran berlangsung siswa antusias dalam mengikuti pelajaran, pelajaran yang dikemas santai membuat siswa lebih nyaman, siswa boleh duduk di lantai sambil berdiskusi, atau menata meja dan kursi sesuai dengan keinginan mereka.

Stiven siswa kelas VII mengatakan dia menyukai pelajaran teks deskripsi, berikut kutipan:

"Pembelajaran Bapak Arie memang selalu memberikan kebebasan kami untuk belajar seperti saat ini, sehingga saya dan teman-teman saling berdiskusi dengan menyenangkan dan tentunya kami menikmati pembelajaran isi teks deskripsi dengan baik."

Rasa bangga yang dirasakan siswa adalah rasa bangga terhadap prestasi teman sekelas yang menjadikan motivasi, sehingga antara siswa di dalam kelas terpacu untuk berbuat lebih minimal sama dengan yang mampu saat itu. Rasa nyaman adalah pelajaran yang dikemas dengan menyenangkan, santai, bermain sambil belajar yang membuat siswa antuasias dalam mengikuti pelajaran.

\section{SIMPULAN DAN SARAN \\ Simpulan}

Berdasarkan hasil dan pembahasan analisis pada pembelajaran menganalisis isi teks deskripsi dengan model numbered head together (NHT) pada siswa kelas VII di SMP Sivaliputta, Kabupaten Kubu Raya, peneliti memperoleh kesimpulan penerapan model NHT dalam pembelajaran menganalisis isi teks deskripsi terhadap siswa kelas VII dilakukan selama empat pertemuan dengan meliputi enam kegiatan yaitu harus ada persiapan, melakukan pembentukan kelompok, mengarahkan diskusi kelompok, melakukan tanya jawab, memberikan simpulan dan memberikan penghargaan. Kegiatan di atas siswa belajar secara kelompok dan mandiri, hal ini dimaksudkan untuk membentuk mental dan kepribadian siswa yang kooperatif serta mandiri, bertanggung jawab, kritis, kreatif, dan percaya diri. Siswa tidak hanya belajar secara teoritis dengan model NHT ini siswa diajak untuk langsung menganalisis drama dalam wujud menunjukan keterampilan.

Faktor pendukung keberhasilan pembelajaran menganalisis isi teks deskripsi dengan model NHT terhadap siswa kelas VII meliputi beberapa aspek, antara lain sarana dan prasarana.

\section{Saran}

Hasil penelitian ini secara teoritis diharapkan dapat memberi kontribusi pemikiran terhadap peningkatan dan inovasi serta pengembangan ilmu pendidikan dan keguruan, yang berkenaan dengan teori kegiatan belajar dan pembelajaran Bahasa Indonesia khususnya pada peningkatan kemampuan menganalisis isi teks deskripsi melalui model pembelajaran Numbered Head 
Together (NHT). Hasil penelitian ini juga dapat dijadikan sebagai sarana yang efektif untuk mengatasi kesulitan belajar dalam pembelajaran menganalisis isi teks deskripsi.

Penelitian ini juga diharapkan dapat memberi masukan bagi guru untuk mengoptimalkan konsep pembelajaran menggunakan model pembelajaran Numbered Head Together (NHT) yang digunakan dalam proses pembelajaran Bahasa Indonesia khususnya pada materi menganalisis isi teks deskripsi. Hasil penelitian ini juga dapat digunakan sebagai masukan positif terhadap peningkatan kualitas pendidikan.

\section{DAFTAR RUJUKAN}

Chaedar, A. (2006). Pokoknya Kualitatif (3rd ed., Vol.3). Jakarta: Pustaka.
Arikunto, S. (2010, 21 Mei 2015). Prosedur Penelitian Suatu Pendekatan Praktik. Jakarta: Rineka Cipta. http://eprints.ums.ac.id/43021/10/D AFTAR\%20PUSTAKAA.pdf.

Harsiati, T. (2017, 12 April 2018). Bahasa Indonesia SMP/MPS Kelas VII. Pusat Kurikulum dan Perbukuan. http://sispahoa.sch.id/perpustakaan.s mp/index.php? $\mathrm{p}=$ cite $\& \mathrm{id}=15904 \& \mathrm{ke}$ ywords $=$.

Soedjito dan Solchan. (2016). Teks Deskripsi sebagai Komunikasi di Dalam Pembelajaran. Bandung: PT. Remaja Rosdakarya.

Sugiyanto. (2010). Model-Model Pembelajaran Aktif, Kreatif, Efektif, dan Menyenangkan. Surakarta: Yuma Pustaka. 